\title{
Summary.
}

I. Toluene and carbon tetrachloride, the latter in excess, condense, giving a mixture of isomeric tolophenone chlorides. On hydrolyzing the reaction mixture $4,4^{\prime}$-dimethylbenzophenone is obtained in yields of $35 \%$ of the calculated.

2. The di-p-tolophenone chloride, similarly to benzophenone chloride, combines with phenol without the aid of catalyst. The resulting $p$-hydroxytriarylcarbinol could only be obtained amorphous. However, enough evidence has been obtained to show that the carbinol exists in two tautomeric modifications, benzenoid and quinonoid.

ANN Arbor, Mich,

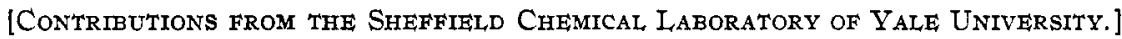

\section{RESEARCHES ON PYRIMIDINES. LXXXVI. THE PRODUCTION OF GLYOXALONES BY HYDROLYSIS OF PYRIMIDINE NUCLEOSIDES. ${ }^{1}$ \\ BY TREAT B. JoEnSON. \\ Received July 18, 1917.}

In recent papers from this laboratory ${ }^{2}$ it has been shown that certain types of hydroxypyrimidine compounds (secondary pyrimidine-nucleosides), which we have succeeded in synthesizing, can be transformed by hydrolysis with acids into derivatives of glyoxaline. A carbon atom is detached from the pyrimidine cycle in these compounds by hydrolysis with production of a five-membered ring in. which the urea group of the original pyrimidine remains intact. The nitrogen atoms of the urea nucleus couple with two carbon atoms in this change, to form a ring of which only one carbon functionated in the original pyrimidine cycle. A transformation of this type is illustrated by the following formulas expressing the rearrangement of the simplest secondary nucleoside of uracil (I) into dimethylglyoxalone ${ }^{3}$ (II):<smiles></smiles>

(I).

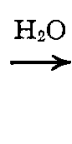<smiles>Cc1c[nH]c(=O)[nH]1</smiles>

(II).

${ }^{1}$ Since this paper was sent to the press an interesting paper has been published by Venable and Moore (Thrs JourNaL, 39, 1750) dealing with the oxidation of uric acid by hydrogen peroxide. They bring forward new data indicating that Scholtz did not have in hand tetracarbonimide but was actually dealing with cyanuric acid. Whether the tetracarbonimide is a precursor of this product remains to be established.

${ }^{2}$ Johnson and Hadley, This Journal, 38, 1844 (rgr6); Proc. Nat. Acad. Sci., 3, 418 (1917); ThIs JOURNAL, 39, 1715, 1919 (1917).

Johnson and Hadley, Loc. cit.; Kunne, Ber., 28, 2040 (I895); Biltz, Ibid., 40, $4801(1907)$. 
The two rearrangements described by us, namely, that expressed above and the corresponding transformation of secondary thymine-nucleoside into ethylmethylglyoxalone ${ }^{1}$ are unique in that the complete changes are brought about by hydrolysis alone and that one carbon atom of the pyrimidine ring is eliminated almost quantitatively in the form of carbon dioxide. The reaction is very probably a general one and of the greatest biochemical interest, but is complicated on account of the fact that it takes place in several stages, and involves the formation of intermediate products which thus far we have been unable to isolate. The purpose of this paper is to present a picture of our conception of the mechanism of these rearrangements, and also to show their relationship to other molecular transformations which have been shown to be characteristic of other types of pyrimidine and purine compounds. In order to properly discuss changes characteristic of the pyrimidine ring it is necessary to take into consideration both pyrimidine and purine combinations, because in the case of purines it is the pyrimidine nucleus of their molecules which functionates in most of the fundamental reactions of this series of compounds. In fact, the earlier investigations on purine compounds revealed to us some of the most unique changes that the pyrimidine ring is capable of undergoing.

The pyrimidine ring, as it.functionates in the mother substance of this series, namely, pyrimidine $\mathrm{N}=\mathrm{CH}-\mathrm{CH}=\mathrm{CH}-\mathrm{N}=\mathrm{CH}$, and re-

lated compounds, is a very stable cycle and it is only by the most energetic treatment (oxidation and reduction) that it can be destroyed in such combinations with formation of acyclic compounds. An addition of hydrogen to the double bonds (saturation) and an incorporation of oxygen into the pyrimidine molecule leads to the production of derivatives which are more sensitive to the action of chemical reagents than the mother substance. These combinations can enter into a great variety of reactions and according to the extent and nature of the changes effected can be subdivided into two specific groups. Group one includes those transformations in which the pyrimidine cycle is completely destroyed with formation of acyclic compounds, while those types of change whereby the ring is destroyed without formation of an acyclic compound, but a new cycle is formed through an intermediate or secondary condensation reaction, are classified under Group two. Characteristic reactions which would be representative of Group one, for example, are those involving the formation of trimethylenediamines (IV) by reduction of pyrimidine compounds $^{2}$ and also the interesting reaction described by Behrend, ${ }^{3}$

1 Johnson and Hadley, Loc. cit.; Gabriel and Posner, Ber., 27, I038 (1894).

2 Johnson and Joyce, This Journal, 38, I385, I854 (1916); Byk, Ber., 36, I9I 7 (I993); Tafel and Weinschenk, Ibid., 33, 3378 (1900).

'Ann., 229, 29 (1885); Behrend and Dietrich, Ibid., 309, 275 (1899). 


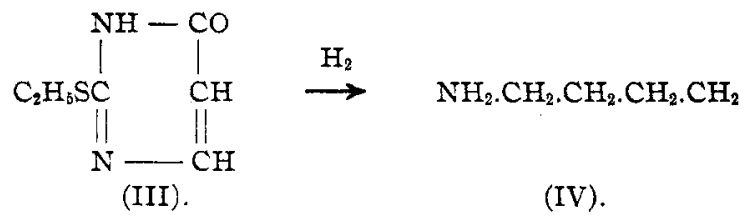

whereby 4-methyluracil (V) and substituted derivatives are converted into oxalic acid and acetylurea (VI) or its derivatives by oxidation. The rearrangements of secondary nucleosides described by us in previous papers are to be classified under Group two, and it is, therefore, this class of reactions only which will receive attention in this paper.<smiles>CCc1cc(=O)[nH][nH]1</smiles>

(V).

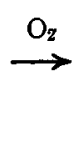

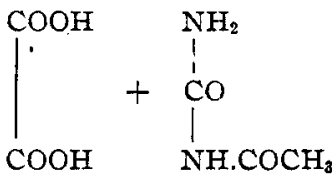

(VI).

As far as we are aware, the first investigators to make the observation that the pyrimidine ring can be converted into a cycle containing one less carbon atom were Liebig and Wohler, ${ }^{1}$ who recorded the interesting fact that uric acid can be transformed smoothly into allantoin by oxidation under special conditions. This hydantoin derivative, which is a normal end product of uric acid metabolism in certain organisms, is formed smoothly, in the laboratory, by oxidation of uric acid with either lead oxide or potassium permanganate in alkaline solution. The mechanism of this important, biological reaction has probably never been accurately interpreted, but, notwithstanding the hypothetical character of our present knowledge of the change, it is true that the final transformation is brought about by the combined influence of oxidation and hydrolysis. It is accompanied by loss of a carbon atom in the form of carbon dioxide and involves a cleavage of the pyrimidine ring between the nitrogen and carbon atoms occupying positions $I$ and 6 , respectively, of the purine molecule. That the glyoxaline nucleus is also ruptured in this process was demonstrated experimentally by Fischer, ${ }^{2}$ who showed that $\mathrm{I}$ - and 7 -methyluric acids are oxidized to the same methylallantoin ( $\alpha$-methylallantoin), while the isomeric $\beta$-derivative ( $\beta$-methylallantoin) is formed by oxidation of either 3 , or 9 -methyluric acids. The simplest, hypothetical explanation of the change of uric acid (VII) to allantoin thus far given is probably that advanced by Behrend. ${ }^{3}$ According to his interpretation the first step in this reaction involves an oxidation of uric acid at the double bond between positions 4 and 5 with formation of a

${ }_{1}$ Ann., 26, 245 (1838); Wheeler, Z. Chem., 746 I 866; Schlieper, Ann., 67, 2 I9 (1848); Neubauer, Ibid., 99, 2 I 7 (1856); Claus, Ber., 7, 227 (1874).

2 Ber., 32, 2723 (1 899).

'Ann., 333, 144 (1904). 
glycol (VIII). ${ }^{1}$ This combination then undergoes a metameric change with destruction of the pyrimidine ring giving a derivative of glycouril (IX), which is finally transformed by hydrolysis into allantoin (XII) with loss of carbon dioxide. The various stages of this process are expressed according to Behrend as follows: The final product of the reaction-<smiles>O=C1NCC2NC(=O)NC2N1</smiles>

(VII).

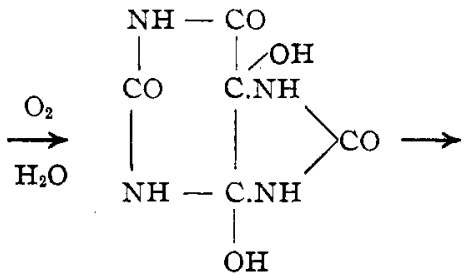

(Uric acid glycol.)<smiles>COC(C)NC1(O)NC(=O)NC1(O)C(=O)O</smiles>

(IX).<smiles>CC(=O)NC1(O)NC(=O)NC1O</smiles>

(X).<smiles>CCCCNC(=O)NC(NC(N)=O)C(N)=O</smiles>

(XI).

(XII).

allantoin-may be represented by either of the two tautomeric formulas (XI) or (XII). Oxidation of uric acid in alkaline solution with hydrogen peroxide is productive of an entirely different result than that obtained when potassium permanganate or lead peroxide are employed. Allantoin is not formed by the action of this reagent, but a new cyclic derivative is formed to which Scholtz ${ }^{2}$ has assigned Formula XV (tetracarbonimide). His observation was confirmed in a later publication by Schittenhelm and Wiener ${ }^{3}$ and also by Ohta." Whether the glycol (VIII) or a glycouril combination (IX) are intermediate products of this interesting reaction remains to be established.

While uric acid is broken down to allantoin when subjected to oxidation in alkaline solution, it is well known that entirely different results are obtained if the operation is applied in acid solutions. Under such conditions the glyoxaline rest of the purine molecule is destroyed and alloxan (XIV) is the characteristic product of oxidation. Here as in alkaline oxidation the glycol (VIII) is the primary product of the reaction and the alloxan results by hydrolysis of this molecule.

${ }^{1}$ Biltz and Heyn, Ber, 45, 1677; 47, 459 (1914).

2 Ibid., 34, 4r 30 (I 90 I).

${ }^{3}$ Z. physiol. Chem., 62, 100 (1909).

4 Biochem. Z., 54, 439; Chem. Zentralb., I913, II, I2 I2, 


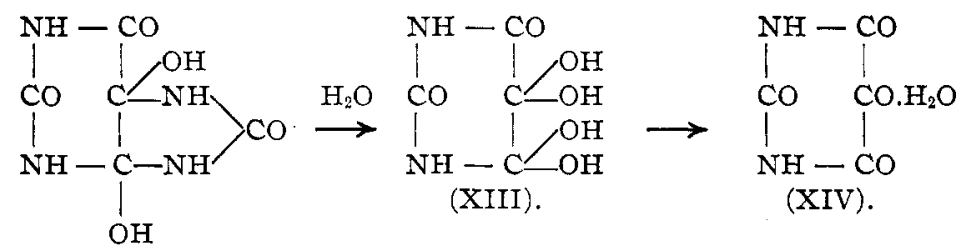

(VIII).<smiles>O=c1[nH]c(=O)[nH]c(=O)[nH]1</smiles>

The glycol of uric acid (VIII) or its derivatives can also break down in such a manner that the pyrimidine ring can be destroyed without the formation of allantoin. This type of decomposition has been thoroughly investigated by Biltz, ${ }^{1}$ who has shown that these glycols can easily undergo cleavage between the nitrogen and carbon atoms occupying positions 3 and 4 in the purine with formation of hydantoin compounds. He has shown that such combinations easily lose their identity as purines by undergoing isomerization in warm, aqueous solution forming representatives of a new class of hydantoin-ureas as expressed by Formula XVI. Several compounds of this type were isolated by Biltz and shown to be characterized by the property of undergoing further unique changes. They lose ammonia easily by treatment with alkali, and are transformed into lactone combinations ( $\mathrm{XX}$ ) (Kaffolid-Abbau), which loose carbon<smiles>O=C1NC(=O)C(O)(O)C(O)NC1=O</smiles><smiles>NC(=O)NC(=O)C(O)(NC(=O)O)C(=O)NC(=O)O</smiles>

(XVI).<smiles>O=C(O)NC(=O)C(O)(NC(=O)O)C(=O)O</smiles><smiles>[Mg][Mg]</smiles>

(VIII).<smiles>NC=O</smiles><smiles>C=[Co]</smiles>
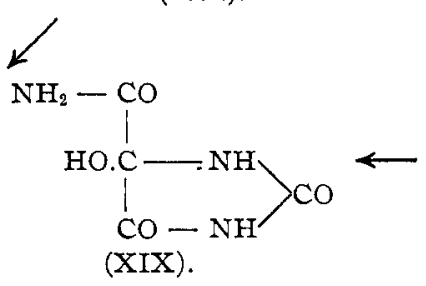<smiles>CC1(NC(=O)O)NC(=O)NC1=O</smiles><smiles>O=C([O-])N[Co]</smiles>

(XVIII).

1 Ber., 43, I5II, I589, 1632 (I910); Biltz and Heyn, Ibid., 45, I666, 1677 (1912); Biltz and Topp, Ibid., 44, I524 (I9II). 
dioxide on hydrolysis and are converted into amide derivatives of hydroxyhydantoin-carboxylic acid (XIX). It is of interest to note here that the ureas represented by Formula XVI can undergo inner condensations with production of bis-hydantoin combinations (XVIII) by treatment with strong acids. ${ }^{1}$

In the case of pyrimidine compounds, the only important data dealing with the conversion of combinations of this series into new cycles is that published by Behrend and his co-workers, ${ }^{2}$ who have investigated very carefully the behavior on oxidation of 4-methyluracil (V) and several of its nitrogen substituted derivatives. This work developed from Behrend's investigations on uric acid. This pyrimidine undergoes most unique changes when subjected to oxidation and, as in the case of uric acid, the operation is productive of different results depending on the conditions under which oxidation is applied. The pyrimidine like uric acid is attacked by potassium permanganate at the double bond between positions 4 and 5 and is converted into trihydroxydihydromethyluracil (XXI), which Behrend and Osten ${ }^{3}$ have shown to be capable of existing in two isomeric modifications. No satisfactory explanation of this isomerism has yet been given, but Behrend concluded that both modifications are true pyrimidines and showed that the $\alpha$-modification (m. p. I28-13 $\mathrm{I}^{\circ}$ ) is easily rearranged to the $\beta$-modification (m. p. II $5^{-I I 7^{\circ}}$ ) by heating in aqueous solution. Here again we have a saturated pyrimidine cycle which can undergo as unique a change as the glycol of uric acid when subjected to oxidation. Potassium permanganate converts both forms in neutral solution into oxalic acid and acetylurea. Oxidation in alkaline solution is productive of an entirely different result and parabanic acid (XXIV) is formed, which finally undergoes hydrolysis in alkaline solution giving oxaluric acid (XXV). An explanation of the mechanism of this last change has been given by Behrend, who has shown that the glycol (XXI) first undergoes a rearrangement in alkaline solution being transformed into acetallanturic acid as represented by Formula XXIII. The same change is also brought about by heating the pyrimidine (XXI) at I IO ${ }^{\circ}$. The formation of this compound involves a hydrolytic cleavage of the pyrimidine ring between positions 3 and 4 , giving an acyclic derivative (XXII) corresponding to Biltz's acid amide (XVI). The urea, being unstable, then undergoes an inner condensation with loss of water forming acetallanturic acid which is oxidized by potassium permanganate to parabanic acid (XXIV). It is of especial interest to note here at this point, that the amino group of the urea in the acyclic compound (XXII)

1 Biltz, Ber., 44, 282 (1911); Ann., 4r3, 77 (1916).

${ }^{2}$ Behrend and Thurm, Ann., 323, I6I (Ig02); Behrend and Grünewald, Ibid., 323, I79; Behrend and Osten, Ibid., 343, I 33 (I906).

3 Loc. cit. 
condenses with a hydroxyl linked to a carbon functionating in position 5, while in the case of Biltz's amides (XVI), where a similar condition exists, the corresponding condensations do not take place in alkaline solutions with formation of hydantoins. On the other hand ammonia splits off easily and lactones (XX) are formed.<smiles>CC1CC2CCC1NC2=O</smiles>

(V).<smiles>CCC(O)C(O)(O)C(=O)NC=O</smiles>

(XXI).<smiles>O=C1NN[W](=O)N1</smiles>
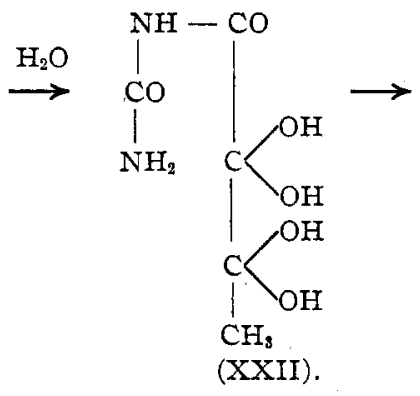

$\stackrel{\mathrm{H}_{2} \mathrm{O}}{\longrightarrow}$<smiles>NC(=O)NC(=O)O</smiles>

(XXIII).

In the light of the above results the rearrangements of secondary pyrimidine-nucleosides into glyoxalones are unique in that they can be brought about by hydrolysis alone, and without first destroying the unsaturated condition of the pyrimidine ring between positions 4 and 5 . In other words, oxidation takes no part in our reactions. In both the cases of uric acid and 4-methyluracil there is no cleavage of the pyrimidine ring until the double bond between positions 4 and 5 is destroyed by oxidation. It is the resulting hexahydro derivative (VIII and XXI) which is so sensitive to the action of hydrolytic agents. In other words, two structural conditions are fulfilled in both the uric acid glycol and the hexahydropyrimidine, namely, complete saturation of the cycle and the presence of a hydroxyl group on carbon 5 , and it is apparently the combined influence of these two conditions which renders the molecule so susceptible to change. The introduction of a hydroxyl group alone into position 5 apparently does not effect the stability of the pyrimidine ring. Such a condition exists in the molecule of isobarbituric acid (XXVI), but this compound can be heated for hours with concentrated hydrochloric acid without change. ${ }^{1}$ Whether the compound can be transformed into glyoxalone (XXVII) by more intense treatment remains to be determined. It is our intention to investigate this problem as soon as time will permit,

1 Johnson and McCollum, J. Biol. Chem., I, 437 (1906). 
and also study the behavior on hydrolysis of aminouracil (XXVIII) and related compounds.

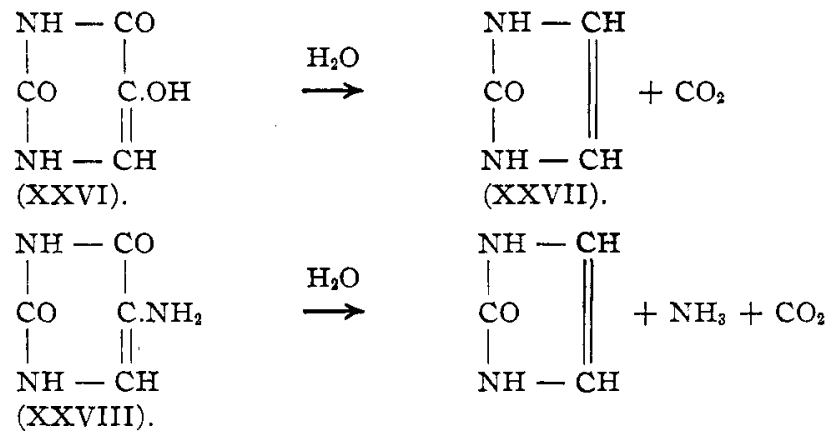

With the above facts now before us, we are in position to discuss the rela tionship of our nucleoside rearrangements to the reactions which have been reviewed, and also to give a simple, theoretical interpretation of the mechanism of these transformations. In the first place attention is directed to certain features of the nucleoside molecule which sharply differentiate these combinations structurally from the hexahydro combinations (VIII) and (XXI), which are known to be so susceptible to chemical change. The nucleosides are derivatives of the stable, unsaturated pyrimidine uracil $\mathrm{NH}-\mathrm{CO}-\mathrm{CH}=\mathrm{CH}-\mathrm{NH}-\mathrm{CO}$, and their in-

stability is apparently due to the presence of the secondary alcohol group substituted in position 4 of the pyrimidine ring. That this alcoholic grouping is able to exert such a pronounced influence on the stability of the cycle is probably explainable by the fact that its hydroxyl group occupies the same atomic position with respect to the nitrogen atom in position I as the active hydroxyl radicle in the two hexahydro combinations (VIII) and (XXI). In all these compounds this group is substituted on a carbon atom occupying position 5 , but in the case of the uric acid glycol and the pyrimidine (XXI) it functionates in the pyrimidine ring while in our compounds it exerts its influence through a side chain. This relationship is clearly brought out by examination of the skeleton formulas below. In other words, the active hydroxyl group occupies, in all these combinations, an atomic position favorable for secondary condensations.

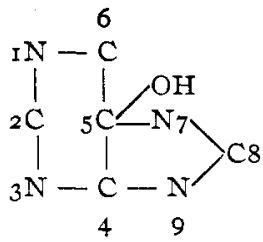

(Uric acid glycol.)

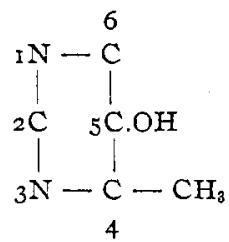

(Hexahydro-pyrimidine.)

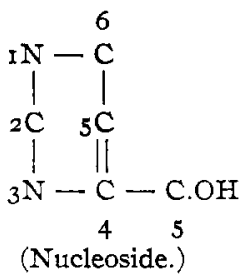


A cleavage of the pyrimidine ring between positions $I$ and 6 would be productive of an atomic arrangement which is favorable for the formation of glyoxaline compounds, and it is our conclusion that we are dealing with a change of this character as the first phase of our reaction. The intermediate product of hydrolysis in our case would therefore be an acyclic compound represented by Formula XXXV.

What seems remarkable to the writer is the fact that the primary pyrimidine-nucleosides or their ethers show no tendency to undergo a similar change and rearrange to glyoxalones, when subjected to the action of halogen acids. Johnson and Hill ${ }^{1}$ and Johnson and Chernoff ${ }^{2}$ prepared combinations of these types (XXIX and XXXII) and showed that they interact normally, when heated with halogen acids, giving the corresponding halides represented by Formulas XXX and XXXIII, respectively. We obtained no evidence of the formation of glyoxalones corresponding to Formulas XXXI and XXXIV.<smiles></smiles>

(XXIX).<smiles>O=C1C=C(CO)C(=O)N1</smiles>

(XXXII).

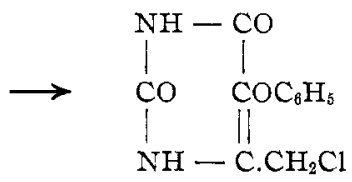

(XXX).

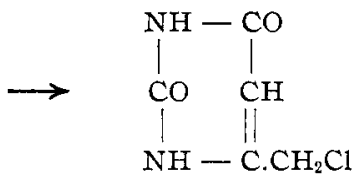

(XXXIII).

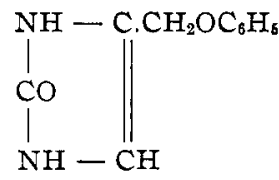

(XXXI).

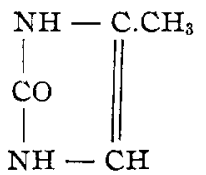

(XXXIV).

Compounds of the type represented by Formula XXXV are apparently unstable under the conditions favorable for hydrolysis of the pyrimidine ring, and easily loose a molecule of carbon dioxide giving a combination, which condenses to a glyoxalone. Theoretically this change might proceed in two ways: First, the acyclic acid (XXXV) could condense with loss of water to give the cyclic compound (XXXVII) which could then loose carbon dioxide with formation of a glyoxalone, or secondly, the reaction might proceed by loss of carbon dioxide first and finally the glyoxalone (XXXVIII) be formed by condensation of the resulting compound (XXXVI). In both cases the cycle (XXXIX) would be an intermediate product. The final change would then involve a migration of hydrogen from a carbon atom in this cycle (XXXIX) to the unsaturated methylene group and a shifting of the double bond into the ring between the two carbon atoms. The rearrangement of the secondary pyrimidine-

1 Am. Chem. J., 48, 296 (igr2).

${ }_{2}^{2}$ This Journal, 35, 585 (I913); 36, I742 (1914). 
nucleoside (I) into dimethylglyoxalone (XXXVIII) therefore may be represented as follows:

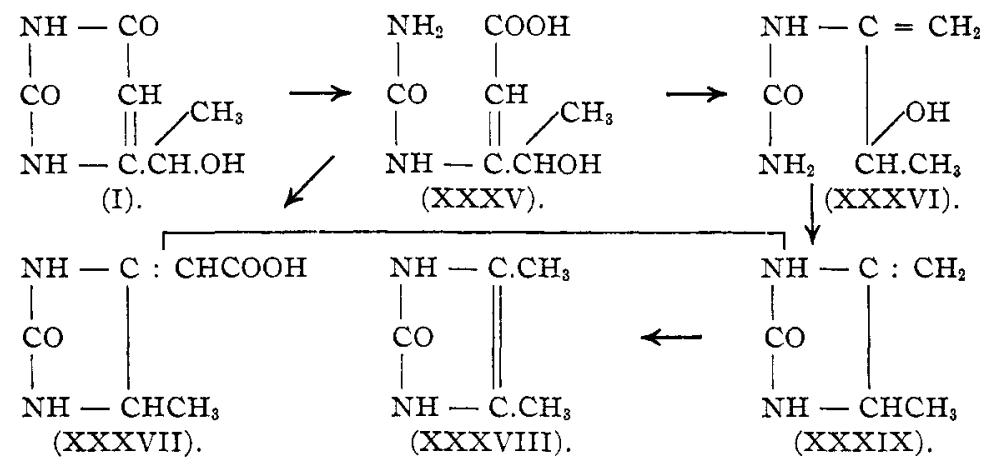

Our results show conclusively that a simple primary or secondary alcoholic grouping in position 4 of the uracil molecule cannot be removed from the pyrimidine by hydrolysis with acids with production of uracil. Whether a lengthening of the carbon chain and the introduction of other hydroxyl groups into such a grouping will weaken the attraction between the carbon atom 4 and the side chain remains to be established. An investigation planned to develop a method of synthesizing tertiary pyrimidine-nucleosides $(\mathrm{XL})$ is now in progress. It will be of interest to determine whether such combinations will undergo rearrangements by hydrolysis giving combinations corresponding to Formula XLI.<smiles>[R]C([R])(O)c1cc(=O)[nH]c(=O)[nH]1</smiles>

$(\mathrm{XL})$.<smiles>[R]C1([R])NC(=O)N[C]1CC(=O)O</smiles>

(XII).

New Haven, Conn.

[CONTRIBUTION FROM THE CHEMICAL LABORATORY OF HaRVARd UNIVERSITY.]

\section{STUDIES IN THE CYCLOPROPANE SERIES.}

[THIRD PAPER.]

By E. P. Kohler, G. A. Hill, AND L. A. Bigelow

Received July 30, 1917.

In the interpretation of two of the transformations of cyclopropane derivatives that were described in previous papers, we assumed the intermediate formation of substances for the existence of which we could secure no direct evidence. Thus, in order to account for the formation of ketolactones by the action of hydrobromic acid on the cyclopropane di-acids, we assumed the intermediate addition of hydrobromic acid, but failed to isolate any products containing bromine. A similar assumption 